\title{
Testemunhos de Sobreviventes ao Desastre de 2011 em Petrópolis: Abordagem Psicossocial em um Campo Ferido
}

\section{Survivor's testimonies from 2011 disaster in Petrópolis: Psychosocial approach in a wounded field}

Testimonios de supervivientes del desastre de 2011 en Petrópolis: Enfoque psicosocial en un campo herido

\author{
Samira Younes-Ibrahim* \\ Universidade Federal do Rio de Janeiro - UFRJ, Rio de Janeiro, Rio de Janeiro, Brasil \\ Marta de Araújo Pinheiro** \\ Universidade Federal do Rio de Janeiro - UFRJ, Rio de Janeiro, Rio de Janeiro, Brasil
}

Catalina Revollo Pardo***

Universidade Federal do Rio de Janeiro - UFRJ, Rio de Janeiro, Rio de Janeiro, Brasil

\begin{abstract}
RESUMO
Este artigo apresenta uma análise dos testemunhos de sobreviventes ao desastre ocorrido em 2011, no Vale do Cuiabá (Petrópolis, RJ), região serrana do Estado do Rio de Janeiro, a partir de uma abordagem psicossocial. Os testemunhos foram coletados sete anos após a tragédia por meio de entrevistas individuais e grupais e mostram que o desastre continua. Dentre os resultados, evidencia-se que as pessoas entrevistadas se percebem como sobreviventes e não como afetados, atingidos ou vítimas; a vivência do abandono permanece com a ausência do Estado; e a precariedade das políticas públicas praticadas fragmentaram as relações comunitárias, gerando comprometimento da comunicação interpessoal. Destaca-se que o desastre permanece enquanto durar o sofrimento social dos envolvidos e que os profissionais que atuam nesse campo necessitam desenvolver uma escuta qualificada.
\end{abstract}

Palavras-chave: desastre 2011, Petrópolis-RJ, psicossociologia, sofrimento social.

\begin{abstract}
This paper presents an analysis of testimonies taken from survivors of 2011 Vale do Cuiabá (Petrópolis, RJ) disaster, located at the highland region of Rio de Janeiro State, based on a psychosocial approach. Testimonies were collected seven years after the tragedy through individual and group interviews. They reveal that the disaster still goes on for those people. Among the results, it is evident that respondents perceived themselves as survivors and not as affected population or victims; the experience of abandonment remains with the absence of State; and the public policies
\end{abstract}


model has shattered communitarian relationship, compromising interpersonal communication. It stands out that the disaster will endure while social suffering from affected people remains, and there is a necessity of developing a more comprehensive and qualified approach for the professionals who take action on disaster situations.

Keywords: 2011 disaster, Petrópolis-RJ, psychosociology, social suffering.

\begin{abstract}
RESUMEN
Este artículo presenta un análisis de los testimonios de los supervivientes del desastre ocurrido en el 2011, en el "Valle del Cuiabá" (Petrópolis, RJ), en la región montañosa del Estado de Rio de Janeiro, a partir de un enfoque psicosocial. Los testimonios fueron recogidos tras siete años de la tragedia por medio de entrevistas individuales y grupales. Para los participantes, el desastre sigue. En los resultados se hace muy evidente que las personas entrevistadas se perciben como supervivientes y no como afectados 0 víctimas; la vivencia de abandono permanece con la ausencia del Estado; y la precariedad de las políticas públicas implementadas fragmentó las relaciones comunitarias, generando fragilidad en la comunicación interpersonal. Se destaca que el desastre permanece mientras dure el sufrimiento social de los involucrados y que existe necesidad de desarrollo de la escucha cualificada para los profesionales que actúan en los desastres.
\end{abstract}

Palabras-clave: desastre 2011, Petrópolis-RJ, psicosociología, sufrimiento social.

\title{
Introdução ${ }^{1}$
}

Nos últimos anos, os desastres têm se multiplicado no planeta e são acompanhados por violências objetivas e simbólicas, estas últimas difíceis de mensurar. Ações emergenciais são executadas, porém, o sofrimento dos sobreviventes continua para além das fases de resposta e recuperação, perdurando através do tempo.

Este artigo tem como objetivo analisar os testemunhos dos sobreviventes ao desastre ocorrido no Vale do Cuiabá, na cidade de Petrópolis, a partir de uma abordagem psicossocial. Esse município é um dos sete atingidos pelo desastre que acometeu a região serrana do Estado do Rio de Janeiro. A contextualização dos desastres no cenário nacional e internacional e a descrição da tragédia de 2011 serão apresentadas no decorrer do artigo. Além disso, são introduzidas considerações sobre a aproximação da psicossociologia e desastres; bem como reflexões sobre a delicada tarefa de estudar um campo com pessoas que vivenciam sofrimentos multidimensionais. São apresentadas, ainda, ao final do artigo, ponderações sobre a escuta dos testemunhos, realizada após sete anos do desastre. Para essa escuta, o recurso escolhido foi a entrevista não diretiva, considerada uma abordagem menos invasiva e de profundo respeito pelo ser humano (Rezola, 1981).

No cenário mundial, muitos países são atingidos por desastres e registram um grande número de mortes, desabrigado ${ }^{2}$, desalojados ${ }^{3}$ 
e deslocamentos forçados. O relatório do Escritório das Nações Unidas para Redução do Risco de Desastres ${ }^{4}$ (UNISDR) mostrou que, nos últimos 20 anos, 1,35 milhões de pessoas morreram devido a desastres. Ressalta-se ainda o número de desabrigados, conforme 0 informe da III Conferência das Nações Unidas para Redução do Risco de Desastres ${ }^{5}$, realizada em março de 2015 , que apontou que, nos últimos 10 anos, cerca de 23 milhões de pessoas ficaram desabrigadas por causa de desastres no mundo. $O$ total de atingidos somou mais de 1,5 bilhões de pessoas.

Quanto ao deslocamento interno forçado ${ }^{6}$ por desastres, o Centro de Monitoramento de Deslocamento Interno ${ }^{7}$ (IDMC - Genebra) mostrou que, em 2017, houve 30,6 milhões de novos deslocamentos no mundo, dado que revela o fato de, a cada segundo, uma pessoa se transformar em um deslocado interno. Avaliando os resultados, 11,8 milhões foram deslocados por conflitos e violência e 18,8 milhões por desastres, ou seja, em 2017, o deslocamento interno provocado por desastres foi superior às migrações por guerras e conflitos.

No Brasil, entre os anos de 2000 e 2017, os desastres resultaram no deslocamento forçado de 6.425.182 pessoas (Folly, 2018), e, somente em 2017, o número de deslocados internos por desastres chegou a 71 mil pessoas, cerca de cinco vezes o de $2016^{8}$. Esse contingente crescente de brasileiros deslocados por desastres passa a compor a população dos que ficam sem moradia, um problema crítico no país.

As informações acima revelam desastres mensurados em números, mas não mostram os danos em outras dimensões, entre elas a psicológica, a social e a cultural, difíceis de computar quantitativamente e que estão em evidência neste artigo.

Da perspectiva da trajetória dos estudos dos desastres, três fases se destacam. Apesar de apresentadas separadamente e por ciclos, na prática elas estão presentes e, dependendo da ótica da gestão, uma ganha mais foco que as outras e direciona as propostas de trabalho.

Segundo Robles e Medina (2008), a primeira fase engloba a cosmovisão religiosa do mundo, quando os desastres eram justificados por ordem divina, geradora de aceitação e impotência por parte da população. O segundo momento contempla a causa dos desastres com uma perspectiva naturalista, apresentando uma visão racional, e o foco na tecnologia ganha destaque. A terceira fase entra no cenário de desastres somente a partir do século $X X$, com a visão psicossocial, quando descortina que as causas dos desastres precisam ser consideradas dentro da conjuntura na qual ele acontece. Assim, abre-se o espaço para o estudo multidisciplinar, no qual o foco está nos sobreviventes e as ações de prevenção e resposta são construídas a partir de estudos de casos. As fases acima permanecem presentes no universo dos desastres, influenciam $o$ pensar $e$, 
consequentemente, guiam as reações e as propostas de ações no processo dos desastres.

O predomínio da visão tecnicista ocupa espaço nos organismos internacionais, com a "prevenção de cima para baixo", que resulta numa política que prioriza a ciência e a tecnologia, ótica direcionada para práticas de assistencialismo e não para ações que promovam mudanças nas causas dos desastres (Revet, 2011). Neste sentido, Pinheiro (2017) aponta que os simulados de evacuação ganham mais destaque do que os estudos sobre os motivos geradores do desastre. Assim, é construída e alimentada a visão de que é necessário e inevitável conviver com o risco.

Considerando-se a compreensão psicossocial, a ótica é não excluir nem a tecnologia nem a ciência, mas construir em conjunto com a inclusão da vivência dos sobreviventes dos desastres, concebendo também as dimensões psicológica, social, cultural e ecológica. A visão a partir da qual a compreensão de desastres é desenvolvida é a base norteadora para a definição das políticas públicas e suas ações.

No cenário brasileiro, as políticas públicas que tratam de desastres são orientadas pela Secretaria Nacional de Proteção e Defesa Civil SEDEC. Dentre a legislação da área, destacamos a Lei 12.608 , de 10 de abril de 2012, formulada após o desastre de 2011. Esta lei criou a Política Nacional de Proteção e Defesa Civil - PNPDEC, e estabeleceu cinco ações para o ciclo de desastre: prevenção, mitigação, preparação, resposta e recuperação. Porém, segundo Valencio (2014), o conceito de desastre se mantém o mesmo desde 1995, ainda com prevalência da visão tecnicista e focada nos riscos em detrimento da abordagem humanista com inclusão do psicossocial. Dentro desta visão tecnicista, os projetos de trabalho norteados por esta lei desenvolvem propostas que tratam das consequências, e, mesmo assim, de forma ineficaz, não conseguindo atender a toda complexidade que um desastre demanda. Esta prática tecnicista foi confirmada na pesquisa realizada no Vale do Cuiabá.

Trazemos duas situações exemplares desta prática colhidas no campo. A primeira mostra a insistência do Instituto Estadual do Ambiente (INEA) na construção de um parque fluvial, apesar de contestações dos moradores.

Porque essa questão de parque fluvial é exatamente em cima disso. Eles não discutiram esses parques fluviais com a comunidade. Eles fizeram o projeto e tentaram... que nós aceitássemos. Entendeu? Que você tivesse uma via pública no fundo do seu quintal. (Sapucaia ${ }^{9}, 2017$ )

Tal cenário, contestado pelos moradores ainda após sete anos, era pauta do INEA, que persistia no assunto: gasto de $\mathrm{R} \$ 5$ milhões de reais para implantação de dois parques fluviais, no Rio Santo Antônio 
e Rio Cuiabá ${ }^{10}$. Mesmo sem a concordância dos moradores e em detrimento de suas necessidades, como a construção de pontes, os parques seguiram nas ações governamentais. A segunda situação, mencionada nos testemunhos, é a separação dos moradores, com a fragmentação dos laços comunitários, sem escuta da importância das relações e das perdas subjetivas existentes em suas histórias de vida. Os testemunhos mostraram que as três esferas governamentais (municipal, estadual e federal) não desenvolveram ações que atendessem as necessidades multidimensionais (física, emocional e social) e que não houve um espaço qualificado de escuta dos sobreviventes. Por esse prisma, resta como ponto-chave o questionamento, no âmbito da abordagem psicossocial: como colaborar para que a voz dos sobreviventes seja considerada nos planejamentos e ações governamentais em desastres?

A análise da produção acadêmica nas diferentes áreas de pesquisa demonstra grandes diferenças. Alves, Lacerda e Legal (2012) realizaram levantamento de trabalhos científicos, nacionais e internacionais sobre a atuação do psicólogo em desastres, produzidos e depositados em bibliotecas virtuais, entre os anos de 2000 e 2010. Os resultados evidenciaram a necessidade de mais estudos $e$ pesquisas na área, principalmente em países em desenvolvimento. Em outro trabalho, Rodrigues, Günther, Vasconcellos, Di Giulio e Boscov (2015), fizeram um levantamento da produção acadêmica brasileira sobre desastres. Averiguaram os grupos de pesquisas entre os anos de 2000 e 2013, com o tema em questão. Foi constatada a predominância das geociências $(41 \%)$ e das engenharias (29\%). Ambas as pesquisas incentivam mais estudos e contribuições das ciências humanas e sociais.

Destaca-se que esses estudos são cada vez mais necessários, já que os desastres ocorrem com frequência no Brasil, com graves desdobramentos multidimensionais que se apresentam de forma violenta, tais como a ruptura abrupta das redes afetivas e sociais, desterritorialização, perdas humanas e materiais, entre outros. Este enredamento implica uma visão amplificada do desastre.

Ao compreender o desastre como um processo e não apenas como um evento pontual (Maskrey, 1993; Quarantelli, 2015; Valencio, 2014), é possível entender que um desastre não acontece da noite para o dia; não deve ser considerado como "natural", pois ele é construído dentro de um contexto histórico, cultural, social, político, ambiental e econômico. O que o produz, e também o alimenta, não vem de fora, não são forças externas; ele é produzido pelo próprio sistema do qual faz parte e não se limita ao tempo cronológico do acontecimento, mas sim ao tempo social e emocional da ruptura causada pelo desastre.

Tendo como referência a perspectiva sintetizada no parágrafo acima e a compreensão de que o desastre se apresenta como um processo, 
cabe questionar, sete anos após o ocorrido, como estarão as pessoas que vivenciaram o desastre de 2011 ?

\section{Contextualização do desastre de 2011}

Entre a noite do dia 11 e a madrugada do dia 12 janeiro de 2011 ocorreu o desastre na região serrana do Estado do Rio de Janeiro, localizada no Sudeste do Brasil. Pela abrangência geográfica e o número de perdas humanas e materiais, recebeu do Sistema Nacional de Proteção e Defesa Civil a denominação de Megadesastre ${ }^{11}$. Chuvas fortes e escorregamentos atingiram diretamente sete municípios: Nova Friburgo, Bom Jardim, Sumidouro, Teresópolis, Petrópolis, Areal e São José do Vale do Rio Preto, causando destruição e deixando grande número de mortos, desaparecidos, desabrigados e desalojados. Diante da intensidade da tragédia, ficou difícil calcular com precisão o número de atingidos em todos os municípios, inclusive o de desaparecidos ${ }^{12}$.

O desastre teve características e abrangência diferentes em cada município. Em Petrópolis, atingiu o terceiro distrito, Itaipava, afetando alguns bairros, principalmente o Vale do Cuiabá. Segundo dados da Secretaria Nacional de Defesa Civil (2011), a região teve 71 óbitos, 187 desabrigados e 6956 desalojados. Considerando-se que a população de Itaipava era de 20.444 habitantes (Censo $2010{ }^{13}$ ), somente o número de desalojados dos bairros atingidos representou $34,22 \%$ da população de todo o distrito.

A região do Vale do Cuiabá faz parte da área rural de Itaipava e apresenta contraste entre os moradores e trabalhadores locais, e a presença dos proprietários de sítios, fazendas, haras e pousadas. Essa disparidade foi chamada pela mídia de "os dois lados do vale". A população possui histórico de anos de moradia no vale, construindo uma convivência próxima. A maioria dos desabrigados e desalojados trabalhava e trabalha nas fazendas e sítios. Uma condição geracional, iniciada por seus ancestrais, muitos sem vínculo empregatício formalizado. Algumas famílias moravam em casas cedidas pelos patrões.

Para alguns sobreviventes, a condição de depender do aluguel social ${ }^{14}$ permanece até os dias de hoje, com ameaças de corte ou a prática de pagamento irregular por parte do Estado ou do município. No município de Petrópolis, em fevereiro de 2014, foram entregues 24 casas construídas pela iniciativa privada em um terreno doado pelos proprietários de uma fazenda da região. Este "arranjo" originou o Condomínio Marília Cápua, formado por 24 casas construídas com recursos de empresários, com dois andares: sala, três quartos, cozinha, dois banheiros, varandas, área, amplo espaço externo e distantes uma da outra. Posteriormente, 50 casas pré-fabricadas 
foram montadas pelo governo do Estado do Rio de Janeiro em outra parte do terreno doado (Pinheiro, 2014), informalmente nomeadas de "Casinhas". Cada uma delas possui sala, cozinha, dois quartos e banheiro, em uma área de 39,41 m2, colocadas lado a lado, feitas com material que permite a passagem de som para todos os ambientes, assim como para a parte externa da construção. Existe grande contraste entre os dois tipos de habitação. Até final de 2017, somente essas 74 casas foram entregues aos sobreviventes.

Quase todos os moradores do Condomínio e das "Casinhas" eram vizinhos no final do Vale do Cuiabá, mas após a tragédia, a mudança na convivência aparece em todos os testemunhos colhidos. Um dos motivos para esta mudança foi a falta de clareza sobre os critérios de distribuição das casas, gerando desconfiança entre os moradores. Os arranjos realizados pelos donos da terra e os órgãos do governo não foram transparentes. Os sobreviventes entrevistados relatam não entender como quem não era proprietário ganhou casa, e quem era proprietário não ganhou ou ganhou a casa menor. A utilização do critério de demarcação de áreas por cores, utilizado em casos de desastres para indicar casas condenadas (vermelhas) ou com possibilidade de retorno (verdes) dos moradores, não foi coerente nem recebeu aprovação dos sobreviventes, assim como a entrega das casas tampouco acompanhou este sistema.

Atualmente, a situação colocada pelos sobreviventes é de que todos se conhecem, porém, parecem estranhos. Existem roubos e uso de drogas no local. Trancas em portas e janelas foram inseridas no convívio. Vidas, tradições, imagens, afetos, espaços eram compartilhados pelo grupo até o desastre de janeiro de 2011, quando foram violentamente banidos de suas histórias, sofrendo com a desterritorialização forçada.

A inserção da psicossociologia no campo de desastres pode oferecer contribuições para lidar com a abrupta ruptura multidimensional (territorial, social, emocional, física, cultural) sofrida pelos sobreviventes.

\section{Metodologia para um campo ferido}

A escolha pela metodologia qualitativa ressoa com o universo de variáveis não quantificáveis que acompanham os desastres socioambientais. Uma opção pela tradução do universo da subjetividade, dos valores, das crenças e das motivações dos sobreviventes: "a abordagem qualitativa se aprofunda no mundo dos significados. Esse nível de realidade não é visível, precisa ser exposto e interpretado, em primeira instância, pelos próprios pesquisados" (Minayo, Deslandes, \& Gomes, 2016). Os procedimentos metodológicos envolveram desde a fase exploratória (Minayo, 2014), 
com o conhecimento do campo, assim como a análise bibliográfica e documental.

O contato inicial com os participantes da pesquisa foi realizado através de lideranças locais, professores, associações comunitárias e religiosas. Um entrevistado indicou outros, constituindo uma rede de indicações. Antes de cada entrevista foi realizada uma explicação clara sobre a pesquisa e seus respectivos objetivos para, posteriormente, ser realizada a leitura do Termo de Consentimento Livre e Esclarecido. O critério de seleção foi ter sido afetado diretamente pelo desastre no Vale do Cuiabá, tendo ficado desabrigado ou desalojado em virtude do desastre. O requisito para participar da pesquisa era ter idade mínima de 18 anos, sem restrição de sexo, nacionalidade, escolaridade, raça, religião ou situação atual de moradia.

A entrevista não diretiva (Rezola, 1981) consiste em um convite para $o$ entrevistado falar livremente sobre o tema em estudo. A postura do entrevistador acompanha o fluxo, as necessidades e as possibilidades do entrevistado, através de condições básicas: congruência, aceitação positiva incondicional e compreensão empática (Wood, 1994). A realização de entrevistas individuais, em dupla e em grupo, atendeu ao movimento e sinalização dos participantes. Foram entrevistadas 13 pessoas: 6 individualmente, sendo que dois indivíduos realizaram também parte da entrevista em dupla; um grupo; e uma dupla.

A partir da compreensão de que a fala é uma das formas de representação do mundo (Bauer \& Gaskell, 2014) interno e externo, a análise qualitativa de conteúdo foi utilizada para compreensão das entrevistas, do diário de campo e do material da fase exploratória.

Com a análise de conteúdo foi possível estudar as informações, sistematizar os dados e a produção teórica. Esta técnica permite "uma leitura de primeiro plano das falas, depoimentos e documentos, para atingir um nível mais profundo, ultrapassando os sentidos manifestos do material" (Minayo, 2014).

Após a conclusão do trabalho de campo, foi realizada a transcrição cuidadosa das entrevistas, respeitando e registrando as pausas, interrupções, repetições, gagueiras, silêncios e expressões corporais. A emoção esteve presente em todas as narrativas, de acordo com a forma de expressão de cada um. Houve momentos em que as palavras não conseguiam traduzir os sentimentos, dando lugar ao silêncio, ao choro ou a expressões "soltas". Também foi devidamente considerada a forma como cada um iniciou a entrevista e a trajetória que escolheu para continuar o testemunho.

A análise de dados começou pela leitura do material das entrevistas e dos registros no diário de campo. Em um segundo momento, foi realizada uma seleção de trechos considerados relevantes para a pesquisa e, posteriormente, foram elencadas duas categorias dos dados empíricos e teóricos: (1) Os dois lados do vale; (2) Memórias 
do desastre de janeiro e de outros desastres no Vale do Cuiabá, com o desenvolvimento de quatro subcategorias:(3) Abandono vivenciado: o emaranhado do poder público, que recebeu duas subcategorias; (4) "Eu era feliz e não sabia"; e (5) Quem sou eu?. O quadro de análise escolhido foi o de procedimento de exploração, priorizado por P. Henry e S. Moscovici (Bardin, 2016). Este não foi determinado previamente, tendo sido proposto a partir da análise do conteúdo das entrevistas.

\section{Aproximação da psicossociologia com o campo de desastres}

A inserção da psicossociologia no campo de desastres pode oferecer contribuições para lidar com a abrupta ruptura multidimensional (territorial, social, emocional, física, cultural) sofrida pelos sobreviventes. Para introduzir esta aproximação, trazemos a possibilidade de articulação entre a psicologia e a sociologia e recorremos ao trabalho realizado por Celso Sá (2015), no qual considerou obras de autores relevantes para a psicologia social e demais ciências humanas e sociais. Em uma das sínteses de seu estudo, o autor destacou que a abordagem psicossocial surgiu para atender a três exigências da realidade: (i) para adicionar a uma disciplina, ou a outra, o que lhes falta para dar conta da situação analisada; (ii) para ser complementar a ambas; ou, ainda, (iii) para constituir uma visão integral, no sentido da transdisciplinaridade.

Os estudos de Denise Jodelet (2018) mostram que a psicossociologia é um conhecimento científico que "... aborda, à luz de processos psicológicos, fenômenos cujo estudo recai, geralmente, nas ciências sociais, em virtude de sua escala e da maneira pela qual eles afetam a vida" (p. 49). Ainda para Jodelet, esta prática apresenta como características "... abertura interdisciplinar, a articulação das dimensões psíquicas, culturais, sociais e organizacionais na abordagem da evolução pessoal e coletiva" (p. 48).

Uma mudança relevante para a reestruturação do pensar e agir em desastres tem relação com a terminologia usada para designar as pessoas que sofrem o desastre. O termo afetado é usualmente utilizado por diferentes instituições para designar as pessoas que foram atingidas ou prejudicadas por desastres (Brasil, 2014 e UNISDR, 2016). Nos movimentos sociais, é possível encontrar o uso de vítima ou atingido; e no âmbito religioso, sofredor (Vargas, 2013). Através da escuta dos testemunhos, foi possível compreender que os entrevistados desconhecem as palavras e os significados pelos quais são nomeados pelos órgãos que oficialmente lidam com desastres.

(...) Eu achei. Eu achei que ia morrer, porque (...) [voz cada vez mais embargada] eu lembrava do meu filho. (...) Quando 
amanheceu que a gente viu que (...) o estrago que tinha feito, tudo que tinha acontecido. (...). Passava helicóptero assim, que já tavam sabendo do que tinha acontecido, e a gente gritava porque a gente (...) sem roupa direito, com frio, com (...) é fome, nervoso e (...) conforme o helicóptero passava a gente gritava mesmo, pra ver, saber que tinha gente ali sobrevivente, né, porque pelo jeito que ficou a impressão é que tinha morrido todo mundo mesmo. (Azaleia, 2017)

Eles se percebem e se reconhecem como sobreviventes: aqueles que escaparam da morte em um desastre e permanecem vivos ${ }^{15}$, muitas vezes sem entender como resistiram enquanto outros não sobreviveram.

Uma questão que requer nossa atenção é quando o sobrevivente é colocado e incentivado a permanecer na condição de vítima. Aceitar as forças externas que modelam esse lugar, como, por exemplo, justificar a causa dos desastres como naturais e decorrentes apenas das forças da natureza, provoca como resposta a sensação de que nada poderia ser feito - pois não haveria como combater esta força que vem de fora - e de que não haveria responsáveis pelo acontecido.

Fortalecer a posição de vítima compromete a construção de si e a resposta à construção de uma comunidade futura (Das, 2008). Nesse sentido, o alerta de Veena Das pode ser ampliado para profissionais que desenvolvem trabalhos e estudos com pessoas que sofrem desastres: o de não promover a implantação deste tipo de discurso com o incentivo de apenas narrar a experiência do sofrimento, pois reforça uma escuta que os mantêm no papel de vítima, o que, infelizmente, é incentivado pelas políticas públicas (Fassin, 2006; Weintraub \& Vasconcellos, 2013). Uma alternativa a este discurso é a prática dos testemunhos como metodologia na psicossociologia (Jodelet, 2018).

Nesse sentido, o preparo para a escuta dos sobreviventes foi realizado desde a aproximação com o campo e a escolha do tipo de entrevista, como já apontado na metodologia utilizada. Também foram consideradas as ponderações de Arjun Apppadurai, em entrevista concedida a Ferreira (2009), sobre o trabalho com memória: o de ser um instrumento que tanto processa a devastação multidimensional sofrida como, ao mesmo tempo, cuida da recuperação do sujeito. Um cuidado necessário na abordagem com pessoas que passaram por rupturas abruptas e não imagináveis em sua vida, como a situação de desastres.

Essa é uma característica desse grupo de sobreviventes quando requer, além de procedimento ético, um cuidado especial. Assim, além de colher os testemunhos, houve o zelo em realizar um 
fechamento do encontro com o entrevistado, a partir do material trazido por ele, tanto nas entrevistas individuais quanto no grupo.

É necessário compreender que, em condições sociais e políticas saudáveis, o passado faz parte do presente. Porém, em situações contrárias, como é o caso deste estudo, o passado fica comprometido e pode atemorizar o presente de forma individual e coletiva quando não há lugar e ajuda qualificada para lidar com o passado (Sarlo, 2007). Todos esses aspectos evidenciam a urgência em desenvolver o preparo do profissional para realizar este tipo de escuta diferenciada (Fassin, 2006). Uma escuta comprometida com os direitos humanos e as necessidades do sobrevivente, sendo ele 0 protagonista de sua história. Esta postura requer disponibilidade interna para uma escuta diferenciada, desenvolvida com a facilitação da compreensão empática, que é uma atitude que envolve "...perceber o quadro de referência interno do outro com acuidade e com os componentes e significados emocionais que pertencem a ele como se você fosse a pessoa (...) sem entretanto perder, em momento algum, a noção de que é como se ..." (Wood, 1994). Foram esses os cuidados tomados para estar em um campo ferido e para a realização das entrevistas com os sobreviventes.

\section{O percurso em um campo ferido}

Estar no campo do Vale do Cuiabá, considerando-se os sete anos passados desde a tragédia, evidenciou que, mesmo para os que já receberam suas casas, o desastre ainda não acabou. Estes sobreviventes possuem um lugar para abrigar seus familiares. Porém, não basta colocar pessoas dentro de uma moradia e depositá-las em um terreno lado a lado para que reconstruam seus laços afetivos e se tornem uma comunidade. Conseguir a casa não colocou ponto final no sofrimento, nem encerrou o desastre. Os sobreviventes vivenciam problemas humanos causados pela ação do poder econômico, político e institucional sobre a vida das pessoas, causando sofrimento social (Kleinman, Das \& Lock, 1996). É um poder que produz modelos de respostas aos problemas sociais que intensificam o sofrimento, como no caso dos sobreviventes do Vale do Cuiabá, um campo ferido.

Assim, para a realização das entrevistas, em 2017, a aproximação com os moradores foi gradativa e aconteceu no tempo dos sobreviventes, que em sua maioria mora nas "Casinhas" e no Condomínio Marília Cápua.

O entendimento da resistência inicial ao estudo foi compreendido como reação ao histórico de excesso de "assédios" da mídia, políticos, autoridades de diferentes esferas governamentais, servidores públicos e voluntários, todos com trabalho e/ou curiosidade a realizar, desconsiderando a privacidade e o momento de fragilidade 
dos sobreviventes. Em conversa informal com Paineira (2017): "(...) não dou mais entrevista. Falava com todos até que um dia me vi na televisão, sendo usada na campanha da pessoa para governador. E, na outra, para campanha do prefeito".

Uma das situações observadas que fragilizaram os moradores foi com relação ao recadastramento dos sobreviventes. O relatório de 2015 da CPI das Chuvas ${ }^{16}$ registra a continuidade deste procedimento doloroso, cinco anos após o ocorrido, revelando desorganização e falta de cuidado com a dor do outro.

Com a compreensão da delicadeza da tarefa de escutar os testemunhos dos sobreviventes do Vale do Cuiabá, houve o compromisso de não repetir posturas e ações prejudiciais e invasivas para as pessoas que iriam participar das entrevistas: um cuidado em não explorar o sofrimento do outro como objeto de estudo (Weintraub \& Vasconcellos, 2013). Tais reflexões evidenciam o lugar do profissional enquanto testemunha (Das, 2008) do vivenciado no processo do trabalho, um lugar gerador de responsabilidade sobre 0 que fazer com os resultados do estudo. Tal situação está evidenciada no testemunho de uma das sobreviventes, referindo-se à entrevista concedida por ela:

É. Que sirva, assim, pra você... ensinar, né, pra outras pessoas sobre isso e quando... você atender, também, pessoas com o mesmo problema, que passaram quase igual, que sirva pra ajudar porque... realmente é difícil. A gente sentir aquela coisa, assim, que vai morrer naquela hora. Muito difícil. (Azaleia, 2017)

Dentro do bojo de responsabilidade do profissional, está a compreensão do desastre como um elemento violento que rompe abruptamente histórias de vida, com resultados danosos tanto no plano individual quanto coletivo. Requer que o profissional não rotule antecipadamente os sobreviventes com classificações psicológicas ou psiquiátricas diante de sinais que podem ser sintomas da ineficácia dos serviços oferecidos a eles e não de uma patologia pessoal. São as questões sociais, políticas e econômicas, estas sim produtoras e conservadoras de sofrimento (Fassin, 2006).

Na memória dos moradores, a ausência de ações do poder público na região do Vale do Cuiabá são anteriores ao desastre. Um poder público que não estava a serviço da comunidade, como destacado no estudo de Pinheiro (2014), que apresentou pesquisa realizada com a comunidade em 2006, com relevância para o fato de que os moradores já não identificavam na região ações socioambientais realizadas pelo governo. Após o desastre, o abandono continuou, como destacado pelos sobreviventes: 
(...) dá uma tristeza muito grande, né? Você ver (...) que pessoas que comandam, comandam (...) sem perguntar aos moradores qual é o desejo deles, o que eles precisam, quais são suas necessidades (...) O [gagueja] relatório, por exemplo, que a gente fez na época para a presidente, surgiu de varias conversas em que nós nos sentimos totalmente abandonados e (...) e vamos que... não tinha como recorrer a ninguém porque qualquer pessoa que a gente recorresse, não dava em nada! Ficava tudo na mesma. Era perda de tempo! (Abacateiro, 2017).

Lembranças de como era a convivência da comunidade antes da tragédia e de agora, quando estão morando no Condomínio e nas Casinhas, retratam a mudança nas relações dos sobreviventes:

Romã: O sentimento, a imagem que eu carrego é sempre do Natal, né?(...) É, Natal, nosso, lá naquela (...) era todas as 32 família, era tudo do sítio, tudo empregado lá, tudo no terreno do sítio.

Rosa: Aí, todo mundo ia na casa da gente.

Romã: Então era, na véspera do Natal e fim de ano, Natal e Ano Novo era uma verdadeira festa, tá entendendo? Tudo unido ali, cada um dava uma coisa, né? (...) a gente pegava, reunia todo mundo. Ninguém dormia aquela noite! Era (...) era churrasco, era (...) muita bebida, era canjica, era milho verde, era tudo que tinha direito! Tudo ali. Muita música! Essa imagem não vai sair nunca! Aqui a gente não faz isso (...). (2017)

O testemunho de Cedro (2017) resume o sentimento dos sobreviventes:

É que eu não (...) aí é que tá, minha filha. Você (...) você tá, é (...) como se diz, cercada de amigos e não tem um amigo (...) infelizmente, sentimento que eu posso te falar é o seguinte: Eu era feliz lá em cima e não sabia (...) Então nós perdemos a... como é que se diz (...) como se fosse perder um filho. Ali era todo mundo agregado. (...) $\mathrm{E}$ os vizinhos que moravam era como fosse parente mesmo da gente.

Diferente de como era antes da tragédia, atualmente existe dificuldade no diálogo, em conversar sobre o que é significativo para cada um, em partilhar celebrações, sentimentos, preocupações e projetos futuros. É possível compreender que, por não haver clareza nos encaminhamentos dos órgãos públicos quanto aos critérios utilizados para a distribuição das moradias, a consequência foi a geração de dúvidas, competição e desconfiança dentro do grupo que 
lutava pelo direito de ter novamente um lar, fragmentando as relações e a capacidade de resistência dos sobreviventes, como pode ser percebido na fala de um dos entrevistados, retratando a conversa com uma representante do poder público:

(...) Ô doutora, Tudo bem! Eu quero que a senhora vá no campo ver a realidade! Porque a senhora tá falando que leigo não questiona laudo técnico, (...) Agora, como é que a senhora me explica que uma casa tá a 30 metros do rio, ela tá na área de exclusão? E tem outra casa que tá a 5 metros do rio e ela tá na área verde, área que você pode morar? (Sapucaia, 2017)

Tal cenário remete ao artigo de Cunha et al. (2015), no qual mostram políticas públicas que foram realizadas em cenários de desigualdades e com ações autoritárias, as quais criaram consequências danosas, promovendo novas vulnerabilidades e novos desastres. Em nossa pesquisa foi possível perceber, nos testemunhos, que o sobrevivente não foi inserido como sujeito ativo nas decisões que iriam definir sua vida e de seus familiares.

Eles não procuram saber! (...) Essas pessoas estavam ali a vida toda, os pais estiveram, os avós estiveram, como é que alguém de fora vem e muda tudo? (...) Agora, continua acontecendo da seguinte forma: Simplesmente não querem saber! (Abacateiro, 2017)

Para Carrillo (2014), apesar de um discurso de "participação comunitária", o que se vê é que políticas sociais que são desenvolvidas seguindo um modelo neoliberal desagregam relações e o agir comunitário, propiciam o assistencialismo, a passividade, o individualismo e a competição entre os moradores. Podemos ver, no testemunho abaixo, como os sobreviventes ficam no meio de um jogo de interesses:

Eu acho que eles fazem, o poder público faz uma coisa desnecessária, pra gastar o dinheiro. E deixa uma coisa necessária, pra arrecadar mais dinheiro. Entendeu? Então, meu ponto de vista é... mais ou menos isso. É (...) é, eles fazem uma coisa supérflua pra arrecadar dinheiro pra fazer uma necessária. Então, isso aí, a gente fica no meio desse fogo cruzado (Sapucaia, 2017).

Ser sobrevivente de desastres deixa marcas, um estigma de como são vistos pela população. 
E tem mais uma coisa, também, que me dói muito. As pessoas, você passou por aquela tragédia toda, aconteceu aquilo tudo e as pessoas te culpam por aquilo. Falam com você assim: Ah, se as pessoas constroem na beira do rio! Tá. E quem não construiu na beira do rio? (Paineira, 2017).

(...) fazer casa na beira do rio, né? A gente não tinha escolha. Se a gente pudesse, a gente escolheria um lugar (Ipê-amarelo, 2017).

Também existe preconceito na forma como o poder público vê os desabrigados e desalojados: que são invasores, culpados por sua própria tragédia, por morarem na área atingida. $O$ diálogo entre dois entrevistados sinaliza a imagem que o Estado tem dos sobreviventes:

Sapucaia: E uma coisa que chateou a gente em 2008 com o poder público, foi o (...) governador vim falar pra gente que Petrópolis era uma (...) é (...) Vale do Cuiabá era uma área de invasores! Em 2011 ele repetiu! Ele repetiu isso!

Abacateiro: Quem que falou isso?

Sapucaia: o Sergio Cabral!

Abacateiro: cretino! Tá preso! (2017)

Lembrando Bauman (2013), estes são exemplos de mecanismos de exclusão, com a naturalização das perdas, quando as vítimas são responsabilizadas pelo desastre e pela condição de desigualdade. Ser culpabilizado pelo desastre também faz parte do universo dos sobreviventes.

\section{Considerações Finais}

Após sete anos, os testemunhos no campo ferido do Vale do Cuiabá demonstram que o sofrimento está presente, evidenciando que o desastre continua para os moradores. Escutar o sofrimento dos sobreviventes leva o pesquisador para o lugar de testemunha de uma parte de suas histórias que, normalmente, permanece invisível. Ao constatar a fragmentação forçada dos laços comunitários, testemunhamos um desastre que não é visibilizado nem atendido pelas ações governamentais.

Estas ponderações foram motivadoras para este artigo no sentido de fornecer reflexões para os sobreviventes e profissionais, com 0 objetivo de contribuir para uma abordagem psicossocial nas políticas de desastres, que estejam em consonância com as demandas dos sobreviventes e que funcionem enquanto durar o sofrimento social dos moradores, independente do tempo cronológico. Este sofrimento é uma categoria que envolve diversas dimensões: física, emocional, 
social, espiritual. Os testemunhos também confirmam que os sobreviventes não são compreendidos em suas reais necessidades, gerando sentimento de descaso e evidenciando o quanto são ignorados, o que potencializa o sofrimento.

Entre outros sinais que evidenciam a continuidade do desastre, destacamos a mudança na convivência entre eles, revelada desde o primeiro testemunho. As relações comunitárias foram devastadas não só pela tragédia, mas em grande parte por um Estado que ignora as responsabilidades que lhe cabem, deixando os sobreviventes abandonados em seu cotidiano, o que contribuiu para a fragmentação da comunidade, comprometendo as relações afetivas e sociais, com o cultivo da desconfiança, apatia, conformismo, medo e a rivalidade entre as pessoas. Na prática, é um abandono vivenciado pelos sobreviventes que afetou a comunicação entre os vizinhos, comprometeu a intimidade nas relações, o compartilhar e a construção do sentido de comunidade.

Entendendo um desastre como um acontecimento social e que precisa ser compreendido como um processo produzido pelo contexto no qual ele está inserido e onde suas causas têm origem, consideramos que a psicossociologia pode contemplar essa multidimensionalidade e fornecer novos elementos para construção multidisciplinar das políticas em desastres, transformando o modelo atual.

Os testemunhos mostram uma direção para os profissionais na construção das ações em desastres: antes de buscar na clínica diagnósticos e soluções medicamentosas para os problemas dos sobreviventes, considerar as questões políticas, sociais e econômicas que fazem parte do contexto do desastre, com destaque para como estão sendo conduzidas as políticas, ou a ausência delas. Os resultados também apontam para a urgência em desenvolver nos profissionais uma escuta qualificada, centrada nos sobreviventes do campo ferido.

\section{Referências}

Alves, R. B., Lacerda, M. A. C., \& Legal, E. J. (2012). A atuação do psicólogo diante dos desastres naturais: Uma revisão. Psicologia em Estudo, 17(2), 307-315. doi:10.1590/S141373722012000200014

Bardin, L. (2016). Análise de Conteúdo. São Paulo: Edições 70.

Bauer, M. W., \& Gaskell, G. (2014). Pesquisa qualitativa com texto, imagem e som: Um manual prático (12a ed.). Petrópolis: Vozes.

Bauman, Z. (2013). Danos colaterais desigualdades sociais numa era global. Rio de Janeiro: Zahar. 
Brasil. (2012). Lei n. 12.608, de 10 de abril de 2012. Institui a Política Nacional de Proteção e Defesa Civil - PNPDEC; dispõe sobre o Sistema Nacional de Proteção e Defesa Civil - SINPDEC e o Conselho Nacional de Proteção e Defesa Civil - CONPDEC. Diário Oficial da União. Brasília, DF: Presidência da República, Casa Civil. Recuperado de http://www.planalto.gov.br/ccivil_03/_Ato20112014/2012/Lei/L12608.htm

Brasil. Ministério da Integração Nacional. Secretaria Nacional de Defesa Civil. (2011). Anuário brasileiro de desastres naturais 2011. Brasília, DF: CENAD. Recuperado de http://www.mi.gov.br/c/document_library/get_file?uuid=e3cab 906-c3fb-49fa-945d-649626acf790\&groupld $=185960$

Brasil. Ministério da Integração Nacional. Secretaria Nacional de Proteção e Defesa Civil. (2014). Anuário Brasileiro de Desastres Naturais 2013. Brasília, DF: CENAD. Recuperado de http://www.integracao.gov.br

Carrillo, A. T. (2014). El Retorno a la comunidade: Problemas, debates y desafios de vivir juntos. Bogotá: Editorial El Búho Ltda.

Cunha, M. B., Porto, M. F. S., Pivetta, F., Zancan, L., Francisco, M. S., Pinheiro, A. B., Souza, F. M., \& Calazans, R. (2015). O desastre no cotidiano da favela: Reflexões a partir de três casos no Rio de Janeiro. O Social em Questão, 18(33), 95-122. Recuperado de http://osocialemquestao.ser.pucrio.br/cgi/cgilua.exe/sys/start.htm

Das, V. (2008). Sujetos del dolor, agentes de dignidade. Bogotá: Universidad Nacional de Colombia.

Defesa Civil. (2012). Capacitação básica em Defesa Civil. Florianópolis: CAD UFSC. http://www.defesacivil.mg.gov.br/images/documentos/Defesa \%20Civil/manuais/Livro_Defesa_Civil_Completo.pdf

Fassin, D. (2006). Souffrir par le social, gouverner par l'écoute: Une configurationsémantique de l'action publique. Politix, 73(1), 137-157. doi:10.3917/pox.073.0137.

Ferreira, T. (2009). Entrevista Arjun Appadurai. Revista Comunicação \& Cultura RCC, (7), 133-140. Recuperado de https://repositorio.ucp.pt/bitstream/10400.14/10449/1/07_07_ Entrevista_Arjun_Appadurai.pdf

Folly, M. (2018). Migrantes invisíveis: A crise de deslocamento forçado no Brasil. Rio de Janeiro: Instituto Igarapé. Recuperado de https://igarape.org.br/wpcontent/uploads/2018/03/Migrantes-invis\%C3\%ADveis.pdf

Jodelet, D. (2018). Inácia D'àvila Neto: Uma prática psicossocial inovadora. In T. B. Maciel, \& C. M. Souza (Orgs.), Inovação e 
trajetos: Comunidade, desenvolvimento e sustentabilidade ( $\mathrm{pp}$ 39-53). Curitiba: Appris.

Kleinman, A., Das, V., \& Lock, M. (1996). Introduction. Daedalus, 125(1), 11-20. Recuperado de http://www.jstor.org/stable/20027350

Maskrey, A. (Comp). (1993). Los desastres no son naturales. Ciudad de Panamá: La Red de Estudios Sociales en Prevención de Desastres en América Latina (La Red). Recuperado de http://www.desenredando.org/public/libros/1993/Idnsn/LosDes astresNoSonNaturales-1.0.0.pdf

Minayo, M. C. S. (2014). O Desafio do Conhecimento: Pesquisa qualitativa em saúde (14a ed). São Paulo: Hucitec.

Minayo, M. C. S., Deslandes, S. F., \& Gomes, R. (Orgs.). (2016). Pesquisa Social: Teoria, método e criatividade. Petrópolis: Vozes.

Nações Unidas para Redução do Risco de Desastres [UNISDR]. (2016). Terminology on disaster risk reduction. Recuperado de http://www.unisdr.org/we/inform/terminology

Pinheiro, F. D. (2014). Quando a casa sai? A Política de reconstrução de moradias para os afetados em desastres socioambientais no Vale do Cuiabá - Petrópolis - RJ (Tese de Doutorado). Universidade Federal Rural do Rio de Janeiro, Seropédica, RJ, Brasil.

Pinheiro, M. A. (2017). O sentido das catástrofes naturais na mídia: da prevenção à adaptação. Anuário Electrônico de Estudios em Comunicación Social "Dissertaciones", 10(2), 39-55.

Quarantelli, E. L. (2015). Uma agenda de pesquisa do século 21 em ciências sociais para os desastres: Questões teóricas, metodológicas e empíricas e suas implementações no campo profissional. O Social em Questão, 33(18), 25-56. Recuperado de rio.br/media/OSQ_33_0_Quarantelli.pdf

http://osocialemquestao.ser.puc-

Revet, S. (2011). Penser et affronter les désastres: Un panorama des recherches en sciences sociales et des politiques internationales. Critique Internationale, 52(3), 157-173. doi: $10.3917 /$ crii.052.0157.

Rezola, J. M. G. (1981). La psicoterapia de Carl R. Rogers: Sus origens, evolucion y relacion con la psicología cientifica ( $3 a$ ed.). Paris: Desclée de Brouwer.

Robles, J. I. \& Medina, J. L. (2008). Manual de salud mental en desastres. Madri: Sintesis.

Rodrigues, A. C., Günther, W. M. R., Vasconcellos, M. P., Di Giulio, G. M., \& Boscov, M. E. G. (2015). Delineamento da produção científica sobre desastres no Brasil no início deste século. Desenvolvimento Meio Ambiente, 34, 61-74. doi: 10.5380/dma.v34i0.38992 
Sá, C. P. (2015). Estudos de psicologia social: História, comportamento, representações, memória. Rio de Janeiro: EdUERJ.

Sarlo, B. (2007). Tempo passado: Cultura da memória e guinada subjetiva. São Paulo: Companhia das Letras.

Tribunal de Contas do Estado do Rio de Janeiro [TCE/RJ]. (2011). Estudos socioeconômicos dos municípios do Estado do Rio de Janeiro: Petrópolis. Recuperado de http://www.cedca.rj.gov.br/pdf/Petropolis.pdf

Valencio, N. (2014). Desastres: Tecnicismo e sofrimento social. Ciência \& Saúde Coletiva: 19(9), 3631-3644. doi:10.1590/1413-81232014199.06792014.

Vargas, M. A. R. (2013). Da "chuva atípica" à "falta de todo mundo": a luta pela classificação de um desastre no município de Teresópolis/RJ (Tese de Doutorado). Universidade Federal de São Carlos, São Carlos, SP, Brasil.

Weintraub, A. C. A. M., \& Vasconcellos, M. P. C. (2013). Contribuições do pensamento de Didier Fassin para uma análise crítica das políticas de saúde dirigidas a populações vulneráveis. História, Ciências, Saúde - Manguinhos, 20(3), 1041-1055. doi:10.1590/S0104-597020130003000016

Wood, J. K. (Org.). (1994). Abordagem Centrada na Pessoa. Vitória: Fundação Ceciliano Abel de Almeida e Universidade Federal do Espírito Santo.

\section{Endereço para correspondência \\ Samira Younes-Ibrahim}

Av. das Américas, 7907, bloco 3, 307, Barra da Tijuca, CEP 22793-081, Rio de Janeiro - RJ, Brasil

Endereço eletrônico: samirayounes@gmail.com

\section{Marta de Araújo Pinheiro}

Universidade Federal do Rio de Janeiro - UFRJ

Instituto de Psicologia

Av. Pasteur, 250, Pavilhão Nilton Campos, Campus da Praia Vermelha, CEP 22290240, Rio de Janeiro - RJ, Brasil

Endereço eletrônico: marta.pinheiro@eco.ufrj.br

\section{Catalina Revollo Pardo}

Universidade Federal do Rio de Janeiro - UFRJ

Instituto de Psicologia

Av. Pasteur, 250, Pavilhão Nilton Campos, Campus da Praia Vermelha, CEP 22290240, Rio de Janeiro - RJ, Brasil

Endereço eletrônico: carevollo@gmail.com

Recebido em: 16/10/2018

Reformulado em: 26/03/2019

Aceito em: 03/04/2019 


\section{Notas}

* Psicóloga. Mestre em Psicossociologia de Comunidades e Ecologia Social EICOS/UFRJ. Membro do LabMemória (EICOS/UFRJ) e da Rede de Cuidados-RJ.

** Professora Titular da Universidade Federal do Rio de Janeiro. Programa de Pósgraduação EICOS - Instituto de Psicologia/UFRJ. Doutora em Comunicação e Cultura (UFRJ).

*** Psicóloga, pós-doutoranda CAPES-PNPD do Programa de Psicossociologia das Comunidades e Ecologia Social do EICOS-UFRJ. Membro do LabMemória (EICOS) e DIASPOTICS (ECO) - UFRJ.

${ }^{1}$ Este artigo tem como base uma pesquisa qualitativa elaborada na dissertação de mestrado na Universidade Federal do Rio de Janeiro, no programa Psicossociologia de Comunidades e Ecologia Social (EICOS), realizada com apoio do Conselho Nacional de Desenvolvimento Científico e Tecnológico - CNPQ.

2 Desabrigados - "pessoas desalojadas ou cuja habitação foi afetada por dano ou ameaça de dano e necessita de abrigo provido pelo sistema". (Brasil, 2014, p. 41). Retirado de http://www.mi.gov.br/defesacivil/publicacoes.

3 Desalojados - "pessoas obrigadas a abandonar temporária ou definitivamente suas habitações, em função de evacuações preventivas, destruição ou avaria grave, decorrentes do desastre, e que não necessariamente carecem de abrigo provido pelo sistema". (Brasil, 2014, p. 41). Retirado de http://www.mi.gov.br/defesacivil/publicacoes.

4 UNISDR (2016). Poverty \& Death: Disaster Mortality 1996-2015. Retirado de https://nacoesunidas.org/onu-90-das-mortes-devido-a-desastres-acontecem-empaises-de-renda-baixa-e-media/.

${ }^{5}$ UNISDR (2015) - Sendai UNISDR (2015) - Sendai Framework for Disaster Risk Reduction 20152030.20 Retirado de https://www.preventionweb.net/files/43291_sendaiframeworkfordrren.pdf

${ }^{6}(. .$.$) internally displaced persons are persons or groups of persons who have been$ forced or obliged to flee or to leave their homes or places of habitual residence, in particular as a result of or in order to avoid the effects of armed conflict, situations of generalized violence, violations of human rights or natural or human-made disasters, and who have not crossed an internationally recognized State border. (ONU, 1998). Retirado de: http://www.un-documents.net/gpid.htm.

https://www1.folha.uol.com.br/cotidiano/2018/06/deslocamentos-internoscausados-por-desastres-aumentam-no-pais.shtml. Acesso em 24/06/2018.

${ }^{8}$ https:www1.folha.uol.com.br. Acesso em 09/06/2018.

9 Respeitando o sigilo dos sobreviventes e acolhendo a característica da forte relação dos mesmos com a terra e a natureza local, nomes de árvores, frutos e flores foram escolhidos para identificar cada entrevistado.

10 A esse respeito, conferir: https://g1.globo.com/rj/regiao-serrana/noticia/seteanos-apos-tragedia-na-serra-do-rj-r-402-milhoes-ainda-estao-previstos-para-

recuperacao-ambiental-em-2018.ghtml

11 O desastre "(...) deixou mais de 45.000 desabrigados e desalojados, caracterizando-se como o maior desastre registrado no Brasil e consolidando, infelizmente, a Serra Fluminense como a região brasileira com o maior quantitativo de vítimas fatais provocadas por desastres naturais ( $40 \%$ do total nacional entre 1988 e 2012)." (Brasil, 2012, p. 63). Retirado de: http://www.mi.gov.br/defesacivil/publicacoes.

12 http://plid.mprj.mp.br/lista-desaparecidos/

13 Instituto Brasileiro de Geografia e Estatística (IBGE). Recuperado de https://cidades.ibge.gov.br/brasil/rj.

${ }^{14}$ O Aluguel Social é um benefício assistencial de caráter temporário, instituído no âmbito do Programa Estadual Morar Seguro, destinado a atender necessidades advindas da remoção de famílias domiciliadas em áreas de risco, desabrigadas em razão de vulnerabilidade temporária, calamidade pública ou em razão de Obras do 
Plano de Aceleração do Crescimento (PAC). Retirado de: http://www.rj.gov.br/web/seasdh/exibeconteudo?article-id=1519686.

15 https://michaelis.uol.com.br/moderno-portugues/busca/portuguesbrasileiro/sobrevivente/.

16 Comissão Especial da Câmara dos Vereadores de Petrópolis para tratar do acompanhamento e fiscalização das determinações da Comissão Parlamentar de Inquérito (CPI) das chuvas do Vale do Cuiabá.

Este artigo de revista Estudos e Pesquisas em Psicologia é licenciado sob uma Licença Creative Commons Atribuição-Não Comercial 3.0 Não Adaptada. 